\title{
A study of infection stages among anemic, non-anemic children and women living in rural areas of Ludhiana district of Punjab, India
}

\author{
Kiran Bains $^{1 *}$, Harpreet Kaur ${ }^{1}$ and Navjot Bajwa ${ }^{2}$ \\ ${ }^{1}$ Department of Food and Nutrition, Punjab Agricultural University, Ludhiana-141004 (Punjab), INDIA \\ ${ }^{2}$ Dayanand Medical College and Hospital, Ludhiana-141001 (Punjab), INDIA \\ *Corresponding author. E-mail: kiranbains68@hotmail.com \\ Received: April 15, 2016; Revised received: September 26, 2016; Accepted: January 4, 2017
}

\begin{abstract}
The effect of iron deficiency on infection stages in 312 women (15-45 years) and 312 children (6-59 months) belonging to the families of agricultural labourers and of small and marginal farmers residing in rural areas of Ludhiana district of Punjab was assessed. The blood hemoglobin levels were below normal in $50.64 \%$ of women and $55.77 \%$ of children. No significant difference in the mean values of C-Reactive protein (CRP) and Alpha-1acid glycoprotein (AGP) was observed among non-anemic and anemic women and children, however the average total leukocyte count was significantly $(p \leq 0.01)$ higher in anemic as compared to non-anemic women and children. CRP indicating acute stage of infection was raised in $10.58 \%$ of women while AGP representing chronic infection was higher in $8.65 \%$ of the women. The CRP values were high in $7.7 \%$ in children, however AGP values were higher in $23.4 \%$ of the children. On the basis of combined levels of CRP and AGP, $11.7 \%$ of non-anemic and $15.3 \%$ of anemic women were detected with infections while $18.8 \%$ of non anemic and $26.0 \%$ of anemic children were in infection state. The results suggest that iron deficiency is quite frequent in children and women. The blood picture showed that more number of anemic women and children were in acute or chronic infection stages as compared to non-anemics, hence, a comprehensive research on the role of iron deficiency anemia in immunity is needed as lower immunity is one of the significant factor of malnutrition which is the most important nutritional challenge for the global community.
\end{abstract}

Keywords: Alpha-1 acid glycoprotein, Children, C-reactive protein, Infections, Women

\section{INTRODUCTION}

Iron deficiency is one of the most common of all the micronutrient deficiencies especially in developing countries. Iron deficiency anemia is a major public health problem in India. A report of National Family Health Survey (NFHS) of India (2015-16) revealed the anemia prevalence in 14 states of India as 44.9 to $71.7 \%$ among children aged 6-59 months with haemoglobin level below $11 \mathrm{~g} / \mathrm{dL}$. Further, 31.3 to $62.7 \%$ adult women (15-49 y) had anemia with haemoglobin level below $12 \mathrm{~g} / \mathrm{dL}$. The data clearly indicated that iron deficiency anemia is a major health problem in India especially in the vulnerable age groups.

Iron metabolism, infection and inflammation are inextricably linked. Although it is established that the major cause of anemia in India is nutritional iron deficiency, but another factor that could have a profound influence in the aetiology of iron deficiency include acute and chronic infections. Upon infection, iron is sequestered in the macrophages and hepatocytes and iron absorption decreases, thus limiting iron to the invading pathogen. This also results in decrease of plasma iron levels, which can lead to iron restricted erythropoiesis and ultimately anemia. Iron deficiency further decreases the resistance to infections through impairment of immune competence of the individuals (Dallman, 1987). Iron deficiency is associated with impairment of cell mediated immunity and the bactericidal activity of neutrophils, thereby increasing the susceptibility of infections (Rehmani and Demmouche, 2014). In light of high prevalence of iron deficiency among Indian children and women, the present study aimed at assessing the effect of iron deficiency on incidence of infections in children and women living in rural Punjab, India

\section{MATERIALS AND METHODS}

The study was conducted in the rural areas of Ludhiana district of Punjab, India. The sampling design of the study was three stage sampling. Ludhiana district is divided into 12 blocks with a rural population of 1339178 living in 918 villages. Thirty clusters (villages) from all blocks were chosen randomly to select 413 households of agricultural labourers and of small and marginal farmers to obtain a sample of 312 children (6-59 months) and 312 women (15-45 years). The number of clusters from each block was proportional to the rural population of each block. The reference subjects were divided into two groups based on their haemoglobin levels. The women and children 
with haemoglobin levels more than the reference values of 12 and $11 \mathrm{~g} / \mathrm{dL}$ (WHO, 2011) were nonanemics while those less than the reference values were designated as non-anemics, respectively.

The information of women subjects regarding their age, physiological status, age at the time of marriage, number of alive children, number of miscarriages and use of nutritional supplements was collected through a questionnaire. Information of the children about age, sex and vaccination was also collected.

The biochemical parameters were studied in Biochemical Analysis Laboratory of Dayanand Medical College and Hospital, Ludhiana, Iron in serum was estimated by Auto Analyzer. C-Reactive protein (CRP), an acute phase protein, was measured on Roche Cobas Mira Analyzer using an immunoturbidimetric principle. Acute phase protein, orosomucoid (Alpha 1-acid glycoprotein) was assessed by ready to use ELISA kit supplied by GenWay Biotech Inc. San Diego,CA. Serum ferritin was measured by chemiluminescent detection method using kit of Roche Diagnostics, Germany. Soluble transferrin receptor (sTfR) was tested using Roche methodology. Complete blood count (CBC) was conducted by Fully Automated Cell Counter (Coulter Corp). The normal ranges mentioned in Standard Operating Procedures (SOP) of each biochemical parameter were taken for reference.

Total leucocytes count (TLC), C-Reactive Proteins (CRP) and Alpha-1 acid glycoprotein (AGP) were used as biochemical markers of different stages of infection. Elevated level of serum CRP and AGP concentrations are indicative of early (acute) and later (chronic) stages of infection, respectively. Taken together these can be used to identify four stages of infection status. The following four group model was used to assess the stages of infection among reference women and children.

\begin{tabular}{lll}
\hline $\begin{array}{l}\text { Stage of } \\
\text { infection }\end{array}$ & Acute phase protein response \\
\hline & Women & Children \\
\hline No infec- & $\mathrm{AGP}<1.2 \mathrm{~g} / \mathrm{L} \&$ & $\mathrm{AGP}<1.0 \mathrm{~g} / \mathrm{L} \&$ \\
tion & $\mathrm{CRP}<6.0 \mathrm{mg} / \mathrm{L}$ & $\mathrm{CRP}<5.0 \mathrm{mg} / \mathrm{L}$ \\
Incubate & $\mathrm{AGP}<1.2 \mathrm{~g} / \mathrm{L} \&$ & $\mathrm{AGP}<1.0 \mathrm{~g} / \mathrm{L} \&$ \\
& $\mathrm{CRP} \geq 6.0 \mathrm{mg} / \mathrm{L}$ & $\mathrm{CRP} \geq 5.0 \mathrm{mg} / \mathrm{L}$ \\
Early con- & $\mathrm{AGP} \geq 1.2 \mathrm{~g} / \mathrm{L} \&$ & $\mathrm{AGP} \geq 1.0 \mathrm{~g} / \mathrm{L} \&$ \\
valescence & $\mathrm{CRP} \geq 6.0 \mathrm{mg} / \mathrm{L}$ & $\mathrm{CRP} \geq 5.0 \mathrm{mg} / \mathrm{L}$ \\
Late con- & $\mathrm{AGP} \geq 1.2 \mathrm{~g} / \mathrm{L} \&$ & $\mathrm{AGP} \geq 1.0 \mathrm{~g} / \mathrm{L} \&$ \\
valescence & $\mathrm{CRP}<60 \mathrm{mg} / \mathrm{L}$ & $\mathrm{CRP}<5.0 \mathrm{mg} / \mathrm{L}$ \\
\hline
\end{tabular}

Percentages, mean, standard deviation and $\mathrm{t}$ values were computed using CPCS 1 software.

\section{RESULTS AND DISCUSSION}

General information of women and children: Table 1 shows that $55.8 \%$ women in the studied group were non-pregnant and non-lactating while $40.1 \%$ were lactating. Majority i.e. $74.4 \%$ were in the age category
Table 1. General information of the reference women and children.

\begin{tabular}{ll}
\hline Parameter & Number (\%) \\
\hline Women (n=312) & \\
\hline Physiological state & \\
Non-pregnant and non-lactating & $174(55.8)$ \\
Pregnant & $13(4.2)$ \\
Lactating & $125(40.1)$ \\
Present age (y) & \\
$15-24$ & $62(19.9)$ \\
$25-34$ & $232(74.4)$ \\
$35-45$ & $18(5.8)$ \\
Age at time of marriage (y) & \\
$<18$ & $22(7.1)$ \\
$18-24$ & $261(83.6)$ \\
$25-32$ & $28(9.0)$ \\
$>32$ & $1(0.3)$ \\
Number of children alive & \\
$<2$ & $103(33.0)$ \\
$2-4$ & $197(63.1)$ \\
$>4$ & $12(3.9)$ \\
No. of miscarriages/abortion & \\
$1-2$ & $22(7.1)$ \\
$3-4$ & $4(1.3)$ \\
$>4$ & $1(0.3)$ \\
$*$ Nutritional supplements & \\
Multi vitamin-Multi mineral & $14(4.5)$ \\
Multi vitamin & $1(0.3)$ \\
Folic acid & $17(5.5)$ \\
Iron & $18(5.8)$ \\
Calcium & $9(2.9)$ \\
\hline
\end{tabular}

\begin{tabular}{ll}
\hline Children (n=312) & \\
\hline Sex & \\
Male & $175(56.1)$ \\
Female & $137(43.9)$ \\
Age (months) & \\
$<12$ & $33(10.6)$ \\
$12-35$ & $133(42.6)$ \\
$36-59$ & $146(46.8)$ \\
Vaccination & \\
Polio & $312(100)$ \\
MMR & $279(89.4)$ \\
Hepatitis & $312(100)$ \\
BCG & $312(100)$ \\
DPT & $312(100)$ \\
Chicken pox & $279(89.9)$ \\
\hline
\end{tabular}

*Multiple Responses; Figures in parenthesis are percentages.

of 25-34 years. Most of the women (83.6\%) were between the age of 18 to 24 years at the time of marriage. The mean age of mothers for bearing upto 4 children lied between 23 to 30 years. Sixty three percent of women had 2-4 children. Miscarriages were reported among $8.7 \%$ of the subjects. Very few subjects used to take nutritional supplements as only 5.5 and 5.8\% were having folic acid and iron supplements. In the survey group, $56.1 \%$ of children were males and the rest were females. $10.6 \%$ of children were below one year of age while 42.6 and $46.8 \%$ children were between the age group of $12-35$ and 36 to 59 months. All the children were vaccinated against polio, hepati- 
Table 2. Percent women and children with low haemoglobin, serum iron and serum ferritin and raised sTfR.

\begin{tabular}{lllll}
\hline & $\begin{array}{l}\text { Women } \\
\mathbf{n = 3 1 2}\end{array}$ & \multicolumn{1}{l}{$\begin{array}{l}\text { Children (6-59 mo) } \\
\mathbf{n = 3 1 2}\end{array}$} \\
\hline Blood Parameters & $\begin{array}{l}\text { Normal } \\
\text { Range }\end{array}$ & $\mathbf{\%}$ & Normal Range & \% \\
\hline Hemoglobin, $\mathrm{g} / \mathrm{dL}$ & $\geq 12$ & 50.64 & $\geq 11.0$ & 55.77 \\
Serum Iron, $\mu \mathrm{g} / \mathrm{dL}$ & $60-180$ & 65.38 & $50-120$ & 84.61 \\
Serum Ferritin, $\mu \mathrm{g} / \mathrm{L}$ & $13-150$ & 54.17 & $\geq 10$ & 71.79 \\
Soluble transferrin receptors, $\mathrm{mg} / \mathrm{L}$ & $1.9-4.5$ & 16.35 & $1.9-4.5$ & 79.81 \\
\hline
\end{tabular}

Table 3. Blood iron status of non-anemic and anemic reference women and children.

\begin{tabular}{lllllll}
\hline & \multicolumn{2}{l}{ Women (15-45 y) } & \multicolumn{3}{l}{ Children (6-59 mo) } \\
\hline Blood Parameters & Non-anemic & Anemic & t-value & Non-anemic & Anemic & t-value \\
\hline Hb. $(\mathrm{g} / \mathrm{dL})$ & $12.86 \pm 0.05$ & $10.58 \pm 0.11$ & $19.62^{* * *}$ & $11.89 \pm 0.06$ & $9.27 \pm 0.09$ & $24.11^{* * *}$ \\
Serum Iron $(\mu \mathrm{g} / \mathrm{dL})$ & $54.67 \pm 2.98$ & $49.88 \pm 2.29$ & $\mathrm{NS}$ & $47.80 \pm 2.37$ & $24.58 \pm 2.22$ & $7.14^{* * *}$ \\
Serum Ferritin $(\mu \mathrm{g} / \mathrm{L})$ & $18.56 \pm 1.59$ & $15.36 \pm 1.59$ & $\mathrm{NS}$ & $12.38 \pm 0.82$ & $5.74 \pm 0.38$ & $7.6^{* * *}$ \\
Soluble transferrin receptors $(\mathrm{mg} / \mathrm{L})$ & $5.27 \pm 0.25$ & $5.60 \pm 0.25$ & $\mathrm{NS}$ & $5.16 \pm 0.18$ & $10.33 \pm 0.27$ & $15.55^{* * *}$ \\
\hline
\end{tabular}

Values are Mean $\pm \mathrm{SE} ; * * *$ Significant at $1 \%$

tis, BCG and DPT. About $90 \%$ of children were vaccinated for MMR and Chicken pox. The excellent vaccination status among children may be attributed to well implementation of National Vaccination Program by Government of India at village level.

Blood iron status of women and children: Table 2 indicates that $50.64 \%$ of reference women had blood haemoglobin $(\mathrm{Hb})$ levels below normal $(\geq 12.0 \mathrm{~g} / \mathrm{dl})$ given by WHO (2011) and low serum iron values i.e. $<60 \mu \mathrm{g} / \mathrm{dL}$ were found in $65.38 \%$ of the subjects. Serum ferritin level, a most reliable indicator of iron deficiency in the absence of infections showed that $54.17 \%$ of women had unsatisfactory ferritin levels $(<12 \mu \mathrm{g} / \mathrm{L})$. The raised levels of sTfR $(>4.5 \mathrm{mg} / \mathrm{L})$ indicates poor iron status and it is unaffected by infection status of the subjects. The values of sTfR revealed the deficiency of iron among $16.35 \%$ of women. This indicated that the actual deficiency prevalence was less, however, higher values of serum ferritin could be due to the presence of sub-clinical infection among good number of subjects. The blood hemoglobin levels of reference children were below normal $(<11.0 \mathrm{~g} / \mathrm{dL})$ in $55.77 \%$ of children whereas, $84.61 \%$ of children had low serum iron levels $(<50 \mu \mathrm{g} / \mathrm{dL})$. Low serum ferritin values $(<10 \mu \mathrm{g} / \mathrm{L})$ were observed in $71.79 \%$ of the subjects, while raised sTfR $(>4.5 \mathrm{mg} / \mathrm{L})$ was found in

Table 4. Percent women and children with raised leukocytes, C-reactive proteins and Alpha 1-acid glycoproteins.

\begin{tabular}{lccc}
\hline $\begin{array}{l}\text { Blood } \\
\text { Parameters }\end{array}$ & $\begin{array}{c}\text { Normal } \\
\text { Range }\end{array}$ & $\begin{array}{c}\text { Women } \\
\mathbf{( 1 5 - 4 5} \mathbf{y}) \\
\mathbf{n = 3 1 2}\end{array}$ & $\begin{array}{c}\text { Children } \\
\mathbf{( 6 - 5 9} \mathbf{m o}) \\
\mathbf{n = 3 1 2}\end{array}$ \\
\hline TLC (10^/ul) & $4-10$ & 23.40 & 59.29 \\
NUET (\%) & $40-75$ & 2.88 & 3.53 \\
LYMPH (\%) & $20-45$ & 10.58 & 64.10 \\
MONO (\%) & $1-10$ & 1.60 & 2.56 \\
EO (\%) & $1-6$ & 12.50 & 19.87 \\
BASO (\%) & $0-1$ & 0 & 0.64 \\
CRP (mg/dl) & $<6.0^{\mathrm{a}}, 5.0^{\mathrm{b}}$ & 10.58 & 7.70 \\
AGP (g/l) & $<1.2^{\mathrm{a}}, 1.0^{\mathrm{b}}$ & 8.65 & 23.40 \\
\hline
\end{tabular}

${ }^{a}$ reference value for women; ${ }^{b}$ reference value for children.
$79.81 \%$ of children. The categorization of children on the basis of degree of anaemia showed that $56.1 \%$ children was anemic, out of which $20.2,33.0$ and $2.9 \%$ of children were mildly, moderately and severely anemic. The data depicts a gloomy picture of iron status of the children in the present study. According to National Family Health Survey in 14 states of India, 44.9 to $71.7 \%$ of children between $6-59$ months were anemic (NFHS-4, 2016). A nationwide study revealed that $67 \%$ of children in Punjab were anemic which included $22 \%$ of mildly anemic, $38 \%$ of moderately anemic and $7 \%$ of severely anemic. More than half of young children in 24 states have anaemia, including 11 states where more than two third of children were anaemic. Seven percent of children in Rajasthan and Punjab are severely anaemic, more than twice the level in India as whole (IIPS, 2008). Present as well as the above mentioned studies presented an inadequate iron status of young Indian children.

Table 3 represents the comparison of iron status of non - anemic and anemic women and children. The results revealed that blood haemoglobin, serum iron and serum ferritin was significantly $(\mathrm{p} \leq 0.01)$ higher in nonanemic children while a significantly $(p \leq 0.01)$ raised sTfRwas observed in anemics as compared to nonanemic children. On the other hand, higher values of serum iron and ferritin were also observed in nonanemic women as compared to anemic women, but the difference was non-significant. Not much difference was observed in sTfR of women from two groups. Herbert et al. (1997) reported that the measurement of serum ferritin iron provides for an accurate assessment of iron status, however inflammation can produce an increase in plasma ferritin concentration. sTfR assay provides more reliable results since chronic diseases have little effect on this. It has been reported to be independent of age and sex (Kohgo et al., 1986).

Infection and micronutrient status: The sub-clinical infection status of reference women and children was determined by biochemical indicators. The data on 
Table 5. Leukocytes, C-Reactive protein (CRP) and Alpha 1-acid glycoprotein (AGP) in the blood of non-anemic and anemic reference women and children.

\begin{tabular}{lcccccc}
\hline & \multicolumn{2}{c}{$\begin{array}{c}\text { Women (15-45 y) } \\
\text { n=312 }\end{array}$} & & \multicolumn{3}{c}{$\begin{array}{c}\text { Children (6-59 mo) } \\
\text { n=312 }\end{array}$} \\
\hline Blood Parameters & Non-anemic & Anemic & t- value & Non-anemic & Anemic & t- value \\
\hline TLC (10^/ul) & $8.36 \pm 0.17$ & $9.01 \pm 0.18$ & $2.56^{* *}$ & $10.46 \pm 0.22$ & $11.11 \pm 0.22$ & $2.07^{* *}$ \\
NUET (\%) & $54.24 \pm 0.69$ & $57.17 \pm 0.80$ & $2.78^{* * *}$ & $42.70 \pm 1.18$ & $40.04 \pm 1.14$ & NS \\
LYMPH (\%) & $35.83 \pm 0.64$ & $35.39 \pm 0.78$ & NS & $47.38 \pm 1.18$ & $50.23 \pm 1.11$ & $1.76^{*}$ \\
MONO (\%) & $6.28 \pm 0.14$ & $4.42 \pm 0.19$ & $1.65^{*}$ & $5.71 \pm 0.17$ & $5.54 \pm 0.18$ & NS \\
EO (\%) & $3.75 \pm 0.26$ & $2.78 \pm 0.21$ & $2.91^{* * *}$ & $4.28 \pm 0.30$ & $4.07 \pm 0.28$ & NS \\
BASO (\%) & $0.17 \pm 0.01$ & $0.16 \pm 0.01$ & NS & $0.22 \pm 0.02$ & $0.21 \pm \pm 0.01$ & NS \\
CRP (mg/dL) & $2.58 \pm 0.30$ & $3.27 \pm 0.62$ & NS & $1.53 \pm 0.27$ & $2.13 \pm 0.37$ & NS \\
AGP (g/L) & $0.82 \pm 0.02$ & $0.83 \pm 0.02$ & NS & $0.81 \pm 0.03$ & $0.80 \pm 0.03$ & NS \\
\hline
\end{tabular}

Values are Mean $\pm \mathrm{SE} ; * * *$ Significant at $1 \%$

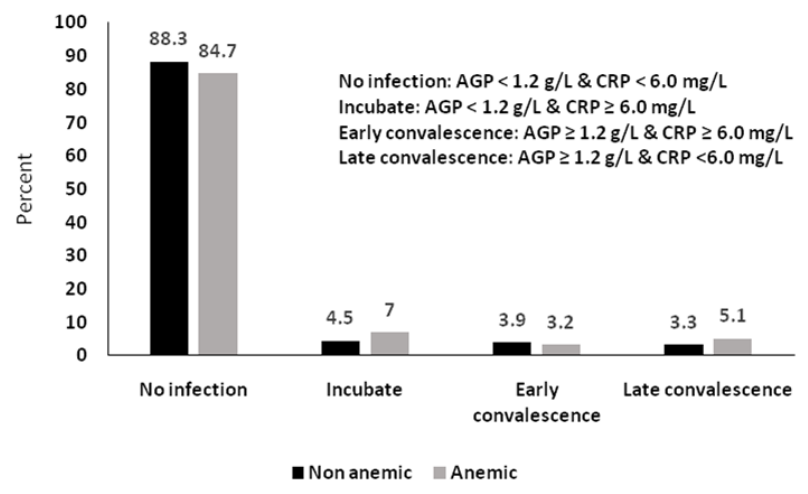

Fig. 1. Stages of infection among reference non-anemic and anemic women (15-45 y).

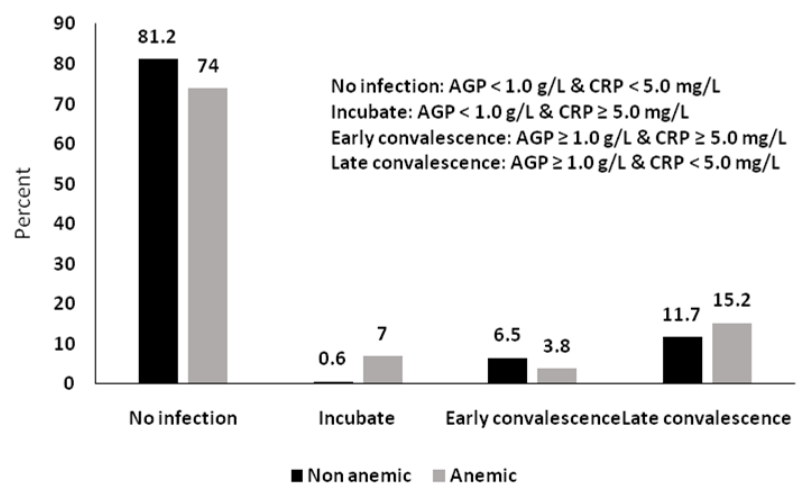

Fig. 2. Stages of infection among reference non-anemic and anemic children (6-59 months).

women and children with raised leukocytes, C-reactive proteins and Alpha 1-acid glycoproteins in table 4 revealed that though the mean TLC value which is an indicator of infection status was within range, $23.40 \%$ of women had raised TLC. Among all leukocytes, lymphocytes and eosinophils were found to be raised in 10.58 and $12.5 \%$ of the women subjects, respectively. Similarly, CRP indicating acute stage of infection was raised in $10.58 \%$ of women while AGP representing chronic infection was on the higher side in case of $8.65 \%$ of the women. In comparison to women, the inflammation was more prevalent among children as $59.29 \%$ of reference children showed raised levels of TLC while 64.1 and $19.87 \%$ of children had raised levels of lymphocytes and eosinophils, respectively. The CRP values representing acute infections were high in $7.7 \%$, however $23.4 \%$ of children were in acute infection stage. Hotz et al. (2011) studied the infection status of 2-5 years old children from Zambia and reported that about $20 \%$ of children had elevated CRP, indicative of early infection; more than half of all children had elevated AGP, indicative of later stages of infection. The infections were lesser prevalent among children in the present study as compared to Zambian children.

Table 5 shows a comparison of levels of immune factors such as leukocytes, C-Reactive protein and Alpha 1-acid glycoprotein in the blood of non-anemic and anemic women and children. No significant differences in mean CRP and AGP values were observed among non-anemic and anemic women and children, however the average total leukocyte count was significantly $(\mathrm{p} \leq 0.01)$ higher in anemic as compared to non-anemic women and children, indicating a positive relationship between low haemoglobin levels and incidence of infection. Rehmani and Demmouche (2014) reported that humeral and cell-mediated immunity which have a crucial role in the different stages of immunogenic are affected by iron deficiency anemia.

The stages of infection among women and children on the basis of combined levels of CRP and AGP are shown in fig. 1 and fig 2 . The results revealed that $11.7 \%$ of non-anemic and $15.3 \%$ of anemic women while $18.8 \%$ of non anemic and $26.0 \%$ of anemic children were in infection stage. Acute infections represented by early convalescence stage were more prevalent in non-anemic women $(3.9 \%)$ and children $(6.5 \%)$ as compared to anemic women (3.2\%) and children $(3.8 \%)$. On the other hand, chronic infections shown as late convalescence stage were higher among anemic women $(5.1 \%)$ and children $(15.2 \%)$ in comparison to their non-anemic counterparts i.e. 3.3 and $11.7 \%$ of women and children, respectively. There are several mechanisms that may explain the effects of iron on the immune system deficiency. DNA synthesis, ribonucleotide reductase enzyme containing iron-initiated is a factor limiting the speed in cell replication and can be 
limited by the iron deficiency (Kulapongs et al., 1974; Moore and Humbert (1984) and Walter et al. (1986).

\section{Conclusion}

The results suggest that iron deficiency anemia prevalence was quite high in the studied group as blood hemoglobin levels were below normal in $50.64 \%$ of women and $55.77 \%$ of children. The blood picture showed that $11.7 \%$ of non-anemic and $15.3 \%$ of anemic women while $18.8 \%$ of non anemic and $26.0 \%$ of anemic children were in either chronic or acute infection stage. The results clearly indicated an association of anemia with infection stage among women and children. The findings of this study also revealed that acute infections were more prevalent in non-anemics while chronic infections were higher among anemics. A comprehensive research on the role of iron deficiency anemia in immunity is needed as lower immunity is one of the significant factor of malnutrition which should be addressed at priority.

\section{REFERENCES}

Dallman, P.R. (1987). Iron deficiency and immune response. Am J Clin Nutr., 4 6:329-334

Herbert, V., Jayctilleke, E., Shaw, S., Rosman, A. S., Giardina P., Grady, R. W., Bowman, B. and Gunter, E.W. (1997). Serum Ferritin Iron, a new test, measures human body iron stores unconfounded by inflammation. Stem Cells, 15:291-296
Hotz, C., Palaniappan, U., Chileshe, J., Kafwembi, E. and Saimusantu, W. (2011). Nutritional survey in central and eastern provinces of Zambia. HarvestPlus, IFPRI, Washington DC, USA.

IIPS. (2008). International Institute for Population Sciences (IIPS) and Macro International. National Family Health Survey (NFHS-3), India 2005-06: Punjab. Mumbai.

Kohgo, Y., Nishisato, T., Kondo, H., Tsushima, N., Nitshu, Y. and Usushizaki, L. (1986). Circulating transferring receptors in human serum. Br. J. Haematol., 64:277-281

NFHS-4 (2016). National Family Health Survey - 4. Ministry of Health and Family Welfare. Government of India.

Kulapongs, P., Vithayasai, V., Suskind, R., and Olson, R.E. (1974). Cell-mediated immunity and phagocytosis and killing function in children with severe iron deficiency anemia. Lancet, 2: 689-699

Moore, L.L. and Humbert, J.R. (1984). Neutrophil bactericidal dysfunction towards oxidant-radical sensitive micro-organisms during experimental iron deficiency. Pediatr Res., 18:789-794

Rehmani, S. and Demmouche, A. (2014). Iron deficiency anemia in children and alteration of the immune system. J Nutr Food Sci., 4:333-343

WHO (2011). Hemoglobin concentrations for the diagnosis of anaemia and assessment of severity. World Health Organization. Retrieved from http://www.who.int/ vmnis/indicators/haemoglobin

Walter, T., Arredondo, S., Arévalo, M. and Stekel, A. (1986). Effect of iron therapy on phagocytosis and bactericidal activity in neutrophils of iron-deficient infants. Am J ClinNutr., 44:877-882 